\title{
Study of EEG Findings in Patients Referred from Psychiatrists
}

\author{
RN CHOWDHURY ${ }^{\mathrm{a}}$, S DAISY ${ }^{\mathrm{b}}, \mathrm{KM} \mathrm{RAHMAN}^{\mathrm{c}}$, SU KHAN ${ }^{\mathrm{d}}$, ATMH HASAN ${ }^{\mathrm{e}}$, ZR KHAN ${ }^{\mathrm{f}}$, B HAQUEg, \\ MA HOQUE ${ }^{\mathrm{h}}$, BA MONDOL ${ }^{\mathrm{I}}, \mathrm{M} \mathrm{HABIB}^{\mathrm{j}}$, QD MOHAMMAD ${ }^{\mathrm{k}}$
}

\begin{abstract}
Summary:
EEG is not so commonly used in patients attending psychiatry department. It is predominantly required to rule out any organic cause behind the behavioral changes. Purpose of this study was to assess the referred cases from psychiatry department and determine the clinical factors associated with an abnormal EEG in patients with psychiatric problem. We retrospectively reviewed and analyzed the data of all the cases referred to EEG lab. of Dept. of Neurology, Dhaka Medical College Hospital from psychiatrist. A total of 50 patients from July 2009 to January 2011 were selected. From the EEG register following information were noted eg. age, sex, socioeconomic status, habitat, rural or urban, clinical features, associated features, probable clinical diagnosis and EEG findings. The results showed that most of the patients belonged to age group 11-20years, comprising $46 \%$ (n-23),
\end{abstract}

a. Dr Rajib Nayan Chowdhury, MBBS MCPS FCPS (Med) MD (Neurology), Assistant Professor of Neurology, Dhaka Medical College Hospital

b. Dr Selina Daisy,, MBBS FAAP (USA) MD (USA), Associate Professor of Neurology, Dhaka Medical College Hospital

c. Dr Kazi Mohibur Rahman, MBBS MD (Neurology) FINR (India), Assistant Professor of Neurology, Dhaka Medical College Hospital

d. Dr Sharif Uddin Khan, MBBS MD (Neurology) FINR (India), Assistant Professor of Neurology, Dhaka Medical College Hospital

e. Dr A T M Hasibul Hasan, MBBS, Registrar, Cardiology, Dhaka Medical College Hospital

f. Dr Zillur Rahman Khan, MBBS FCPS (Psychiatry), Assistant Professor of Psychiatry, National Institute of Mental Health, Dhaka

g. Dr Badrul Haque, MBBS PhD, Indoor Medical Oficer, Dept of Neurology, Dhaka Medical College Hospital

h. Dr Md Azharul Hoque,, MBBS FCPS (Med) MD (Neurology) MACP (USA), Associate Professor of Neurology, Dhaka Medical College Hospital

i. Dr Badrul Alam Mondol, MBBS MD (Neurology), Associate Professor of Neurology, Dhaka Medical College Hospital

j. Professor Monsur Habib,, MBBS FCPS (Med) MD (Neurology) MRCP (UK) FRCP (Edin), Professor of Neurology, Dhaka Medical College Hospital

k. Professor Quazi Deen Mohammad, MBBS FCPS (Med) MD (Neurology) Fellow of Neurology (USA), Professor Head, Dept of Neurology, Dhaka Medical College Hospital

Address of Correspondence: Dr Rajib Nayan Chowdhury, Assistant Professor of Neurology,

Dhaka Medical College Hospital. Email: rajibchow86@yahoo.com Received: 22 May, 2011

Accepted: 20 September, 2011
$66 \%$ (n-33) were female. Though the total rate of abnormal EEG in psychiatry patients are low (n-20). $44 \%$ of the patients having seizure as the presenting complaint had the largest number of EEG abnormality (n-16), p value $<.001$. Patients with primary psychiatric disorders did not have any epileptiform activity (n-22). Where as most of the patients (n27) who were undiagnosed at the time of referral had the largest number of EEG abnormality (n-19), p value $<.002$. So any patient presenting to psychiatry department with seizure disorder or any patient with diagnostic confusion should be evaluated with EEG.

Key words: Generalized epilepsy (GE), Localization related epilepsy (LRE), psychogenic nonepileptic seizures (PNES).

(J Bangladesh Coll Phys Surg 2012; 30: 24-29)

\section{Introduction:}

Electroencephalography (EEG) is the recording of electrical activity along the scalp produced by the firing of neurons within the brain. In clinical contexts, EEG refers to the recording of the brain's spontaneous electrical activity over a short period of time, usually 20-40 minutes, as recorded from multiple electrodes placed on the scalp. In neurology, the main diagnostic application of EEG is in the case of epilepsy, as epileptic activity can create clear abnormalities on a standard EEG study. A secondary clinical use of EEG is in the diagnosis of coma, encephalopathy, and brain death. ${ }^{1}$

The electroencephalogram is believed to be of limited value in psychiatry. This is particularly true for patients with neurosis and functional psychosis. With the advent of modern imaging like CT scan or MRI, EEG has got limited value in organic states like tumors, stroke and other focal brain disorders, although former gives a structural and later gives functional assessment of cerebral function. EEG is the investigation of choice in suspected cases of epilepsy and can differentiate between seizure and pseudo seizure. There is well documented relationship between psychosis and epilepsy. In particular temporal lobe abnormalities may present with mental illness. ${ }^{2}$ Gruhle, Hill and Pond found psychotic states in epileptic patients that closely resembled schizophrenia. In their review they found 
lesions in temporal lobe in most of the patients. Slater studied 69 epileptic patients presenting with a schizophreniform psychosis; $80 \%$ had temporal lobe epilepsy (TLE). ${ }^{3,4,5}$

There are doubts and arguments about the role of EEG in psychiatry. Although psychiatrists send patients for EEG where there is doubt about seizure, pseudo seizure and psychosis. With this background the aim of this study is to correlate various clinical presentations of psychiatric patients to EEG findings and to guide clinicians in cases where EEG is indicated to differentiate between a primary psychiatric disorder and epilepsy.

\section{Materials \& methods:}

This is a retrospective observational study carried out in EEG lab of Department of Neurology of DMCH from July 2009 to January 2011. All the patients referred from Department of Psychiatry or psychiatrists for EEG were enrolled for the study. Information of non co-operative patients or EEG with marked artifact were discarded Data of first 50 patients were taken from EEG register. From the EEG register following information were noted eg. age, sex, socioeconomic status, habitat, rural or urban, clinical features, associated features, probable clinical diagnosis, EEG findings and diagnosis. EEG was done in international 10/20 system using surface electrodes. After proper recording EEG were analyzed and reported by two Neurologist of Department of Neurology of DMCH. EEG showing focal epileptiform activity was labeled as LRE (Localization Related Epilepsy) and generalized epileptic activity was labeled as GE (Generalized Epilepsy). Data were recorded and analyzed using SPSS system.

\section{Results:}

The number of cases referred from the department of Psychiatry to Neurology for EEG evaluation is sparse. We just had 50 cases from the psychiatry department. We carried out a retrospective observation of patients from hospital records. The results of observation are quite interesting. Most of the patients belong to age group 11-20years, comprising $44 \%(n-22)$ and 62\% of patients was below 20years of age. $66 \%$ of the patients were female (Table-I). 34\% patients experienced sudden onset of symptoms whereas 66\% had gradual onset of illness. Symptom analysis revealed that seizure (true or pseudo seizure) was present in 22 patients (44\%) (Table-II). At the time of referral $54 \%$ of the patients did not have any specific diagnosis on underlying psychiatric disorder (TableIII). Analysis showed a strongly positive association between seizure event at presentation and likelihood of getting an abnormal EEG diagnosis, p value 0.0001 (Table-IV). During referral 46\% patient had specific diagnosis of underlying psychiatric disorder. But only 1 patient had a LRE diagnosed. Rest of the patients (n-27) who were undiagnosed had the highest number of EEG positive cases (Table-V).

\section{Table I}

Socio demographic profile of the patients

\begin{tabular}{clcc} 
Parameter & & $\mathrm{n}$ & $\%$ \\
\hline Age & $<10$ yr & 9 & 18 \\
& $11-20$ yr & 22 & 44 \\
& $21-30$ yr & 9 & 18 \\
& $31-40$ yr & 7 & 14 \\
& $41-60$ yr & 2 & 4 \\
& $>60$ yrs & 1 & 2 \\
Sex & Male & 17 & 34 \\
& Female & 33 & 66 \\
Habitat & Rural & 32 & 64 \\
& Urban & 18 & 36 \\
Socioeconomic status & Lower class & 22 & 44 \\
& Middle class & 25 & 50 \\
& Higher class & 3 & 6 \\
\hline
\end{tabular}

Table I: Most of the patients belong to age group 1120years, comprising $44 \%(n-22)$ and $62 \%$ of patients was below 20years of age. 66\% of the patients were female. Majority of them were from rural areas (64\%) and belonged to middle class (50\%). 
Table II

\begin{tabular}{clcc}
\multicolumn{2}{c}{ Clinical symptoms and associated features } \\
Parameter & $\mathrm{n}$ & $\%$ \\
\hline Onset & Sudden & 17 & 34 \\
& Gradual & 33 & 66 \\
Duration & Years & 21 & 42 \\
& Months & 18 & 36 \\
& Weeks & 6 & 12 \\
& Days & 2 & 4 \\
& Seizure & 22 & 44 \\
& Unconsciousness & 22 & 44 \\
& Altered behavior & 21 & 42 \\
& Headache & 13 & 26 \\
& Burning head & 7 & 14 \\
& Psychosis & 7 & 14 \\
& Others & 8 & 16
\end{tabular}

Associated features

$\begin{array}{lcc}\text { Family History } & 5 & 10 \\ \text { Birth injury } & 3 & 6 \\ \text { Cerebral palsy } & 5 & 10 \\ \text { H/O encephalitis } & 3 & 6 \\ \text { Substance abuse } & 4 & 8 \\ \text { Family dispute } & 5 & 10 \\ \text { Mental retardation } & 4 & 8 \\ \text { Decreased school } & 7 & 14 \\ \text { performance } & & \end{array}$

Drug History

\begin{tabular}{lcc} 
Antidepressant & 12 & 24 \\
Anti epileptic & 10 & 20 \\
Antipsychotic & 7 & 14 \\
No drugs & 21 & 42 \\
\hline
\end{tabular}

Table II: 34\% patients experienced sudden onset of symptoms whereas $66 \%$ had gradual onset of illness.
Symptom analysis revealed that seizure (true or pseudo seizure) was present in 22 patients (44\%), unconsciousness in 22 patients and altered behavior in 21 patients. history of cerebral palsy was found in $10 \%$ and Birth asphyxia in 6\%. Many of them received antidepressant (24\%) and antiepileptic (20\%) drugs.

\section{Table III}

\section{Underlying psychiatric disorder and EEG}

\begin{tabular}{|c|c|c|c|}
\hline Parameter & & $\mathrm{n}$ & $\%$ \\
\hline Underlying psyc & atric disorder & & \\
\hline & Conversion disorder & 6 & 12 \\
\hline & Somatoform disorder & 3 & 6 \\
\hline & Depression & 6 & 12 \\
\hline & Schizophrenia & 7 & 14 \\
\hline & Others & 1 & 2 \\
\hline & Undiagnosed & 27 & 54 \\
\hline EEG Diagnosis & Normal & 30 & 60 \\
\hline & LRE & 14 & 28 \\
\hline & GE & 6 & 12 \\
\hline EEG Findings & Normal & 30 & 60 \\
\hline & Spike and wave & 14 & 28 \\
\hline & Sharp and wave & 4 & 8 \\
\hline & Focal slow wave & 2 & 4 \\
\hline Site of epileptifo & $\mathrm{n}$ activities & & \\
\hline & Temporal lobe & 8 & 16 \\
\hline & Frontal lobe & 2 & 4 \\
\hline & Paracentral & 3 & 6 \\
\hline & Hemispheric & 1 & 2 \\
\hline & Generalized & 6 & 12 \\
\hline
\end{tabular}

Table III: At the time of referral 54\% of the patients did not have any specific diagnosis on underlying psychiatric disorder. Conversion disorder was present in 6 cases, Somatoform disorder in 3, depression in 6 and schizophrenia in 7 cases. EEG was normal in 60\% cases, LRE in $28 \%$, GE in $12 \%$. Most common EEG abnormality was in the form of Spike and wave in $28 \%$, most common location was Temporal lobe (16\%). 
Table IV

\begin{tabular}{clcccc}
\multicolumn{5}{c}{ Seizure and EEG diagnosis } \\
Seizure & Normal & LRE & GE & Total & \\
\hline Present & Count & 5 & 12 & 5 & 22 \\
& \% within seizure & 22 & 54 & 22 & 100 \\
& \% within EEG Diagnosis & 16 & 85 & 83 & 44 \\
& \% of total & 10 & 24 & 10 & 44 \\
\multirow{5}{*}{ Absent } & 25 & 2 & 1 & 28 \\
& Count & 89 & 7 & 2 & 100 \\
& \% within seizure & 83 & 14 & 16 & 56 \\
& \% within EEG Diagnosis & 50 & 4 & 2 & 56 \\
Total & \% of total & 30 & 14 & 6 & 50 \\
& Count & 60 & 28 & 12 & 100 \\
& \% within seizure & 100 & 100 & 100 & 100 \\
& \% within EEG Diagnosis & 60 & 28 & 12 & 100 \\
Chi-Square test & \% of total & $\mathrm{df}$ & & & $p$ \\
& Pearsons Chi-Square & 2 & 0.0001 & & \\
\hline & Likelihood ratio & 2 & 0.0001 & & \\
\hline
\end{tabular}

Table V

\begin{tabular}{|c|c|c|c|c|c|}
\hline \multicolumn{6}{|c|}{ Underlying psychiatric disorder and EEG diagnosis } \\
\hline Underlying Psychiatric disease & & $\mathrm{N}$ & LRE & GE & Total \\
\hline \multirow[t]{3}{*}{ Conversion Disorder } & Count & 6 & 0 & 0 & 6 \\
\hline & \% within EEG Diagnosis & 20 & 0 & 0 & 12 \\
\hline & $\%$ of total & 12 & 0 & 0 & 12 \\
\hline \multirow[t]{3}{*}{ Somatoform Disorder } & Count & 3 & 0 & 0 & 3 \\
\hline & \% within EEG Diagnosis & 10 & 0 & 0 & 6 \\
\hline & $\%$ of total & 6 & 0 & 0 & 6 \\
\hline \multirow{3}{*}{ Depression } & Count & 6 & 0 & 0 & 6 \\
\hline & \% within EEG Diagnosis & 20 & 0 & 0 & 12 \\
\hline & $\%$ of total & 12 & 0 & 0 & 12 \\
\hline \multirow[t]{3}{*}{ Schizophrenia } & Count & 7 & 0 & 0 & 7 \\
\hline & \% within EEG Diagnosis & 23 & 0 & 0 & 14 \\
\hline & $\%$ of total & 14 & 0 & 0 & 14 \\
\hline \multirow[t]{3}{*}{ Others } & Count & 0 & 1 & 0 & 1 \\
\hline & \% within EEG Diagnosis & 0 & 7 & 0 & 2 \\
\hline & $\%$ of total & 2 & 0 & 0 & 2 \\
\hline \multirow[t]{3}{*}{ Undiagnosed } & Count & 8 & 13 & 6 & 27 \\
\hline & \% within EEG Diagnosis & 27 & 93 & 100 & 54 \\
\hline & $\%$ of total & 16 & 26 & 12 & 54 \\
\hline \multirow[t]{2}{*}{ Total } & Count & 30 & 14 & 6 & 50 \\
\hline & $\%$ of total & 60 & 28 & 12 & 100 \\
\hline \multirow[t]{3}{*}{ Chi-Square test } & & df & & & $p$ \\
\hline & Pearsons Chi-Square & 10 & & .002 & \\
\hline & Likelihood ratio & 10 & & .000 & \\
\hline
\end{tabular}


Table IV: Analysis showed a strongly positive association between seizure event at presentation and likelihood of getting an abnormal EEG diagnosis, $\mathrm{p}$ value 0.0001

Table V: During referral $46 \%$ patient had specific diagnosis of underlying psychiatric disorder. But only 1 patient had a LRE diagnosed. Rest of the patients (n27) who were undiagnosed had the highest number of EEG positive cases. The association of underlying psychiatric disorder and positive EEG diagnosis is highly significant, p value $<.002$.

\section{Discussion:}

The value of EEG in psychiatry is an issue of debate since the advent of these electrophysiological studies in the 1930. Interestingly there are few credible studies in this area in home and abroad, and much of the earlier studies had poor research design and hence unwarranted conclusions.

Among the cases in our study, 66\% (n-33) were female and $34 \%(n-17)$ were male. Here female outnumbers male. Most of the patients belong to age group 1120years, comprising $44 \%(n-22)$ and $62 \%$ of patients was below 20years of age. Next was the age range from $0-10$, having 9 patients. Only one patient was above 60 years. In this study 64\% (n-32) of the patients were from urban areas and 36\% (n-18) from rural area. 44\% (n22 ) of patients belonged to lower social class and only $6 \%$ belongs to higher class. Onset of illness was gradual in $66 \%$ of the patients. $42 \%$ patients suffered for years together while $12 \%$ waited for weeks before getting their EEG done. Here it is evident that patients with combined psychiatric neurologic symptoms suffer for long time before getting consultation from specialists. Analysis of symptoms revealed that seizure (true or pseudosizure) was present in 44\% (n- 22) patients, in 44\% (n-22) patients there was history of unconsciousness, 21 patients had history of altered behavior, headache in 13 patients and psychotic features were present in 4 patients. Psychogenic nonepileptic seizure (PNES) or pseudoseizures are common at epilepsy centers, where they are seen in 20-30\% of patients referred for refractory seizures. PNES are probably also common in the general population, with an estimated prevalence of 2-33 cases per 100,000 populations. Misdiagnosis of epilepsy is common. Misdiagnosis occurs in approximately $25 \%$ of patients with a previous diagnosis of epilepsy that does not respond to drugs. Most cases of misdiagnosed epilepsy are eventually shown to be psychogenic nonepileptic seizures (PNES) or, more rarely, syncope. ${ }^{6,7,8} 44 \%(n-17)$ of the patients with abnormal EEG findings had seizure at onset of illness. Analysis revealed a strong association between seizure and EEG abnormality, p value .0001 (Table-IV). So any patient with seizure that visits psychiatry department should be evaluated with EEG for further management. Out of 50 patients $10 \%(n-5)$ patients had cerebral palsy, 8\% (n- 4) patients had mental retardation, there was presence of birth injury in 3 patients, and 5 patients had history of family dispute. Bruck showed the overall prevalence of epilepsy was $62 \%$ in cerebral palsy. Incidence of epilepsy was predominant in patients with hemiplegics and tetraplegic palsies: $70.6 \%$ and $66.1 \%$, respectively. $9,10,11$. The cumulative risk of seizures and epilepsy was investigated in a prospectively identified cohort of 221 children with mental retardation (MR) born between 1951 and 1955 in Aberdeen, Scotland. By age 22 years, 33 (15\%) had epilepsy. ${ }^{9}$ At the time of referral for $24 \%$ (n-12) were on antidepressant, $20 \%$ on antiepileptic, $14 \%$ were on antipsychotic drugs where as $42 \%$ were without these drugs. Probable psychiatric diagnosis was Dissociative disorder in 6 patients, Somatoform disorder in 3 patients, Depression in 6 patients, Schizophrenia in 7 patients and diagnosis was not mentioned in 27 patients. 1 patient thought to be of psychiatric disorder actually had LRE (Table- III) Analysis shows that $50 \%$ of the conversion disorder patients had seizure at onset, while $63 \%$ of the patients who did not have a definite diagnosis of psychiatric illness had seizure at presentation. Co morbidities of epilepsy and psychiatric disorder is common, yet the most common are depression, nervousness, anxiety, PNES, and less common being Schizophrenia and psychosis. ${ }^{10-14}$

EEG revealed that 60\% (n-30) had normal findings, 28\% (n-14) had Localization related epilepsy (LRE), and 12\% (n-6) had Generalized epilepsy (GE). 54\% of the patients who were undiagnosed at the time of referral, had the most number of EEG abnormality. Analysis showed a strong association between underlying psychiatric disorder and EEG negativity, p value .002 (table-V). This signifies the role of EEG in any patient of psychiatry with diagnostic confusion. Out of 16 patients of LRE 8 originated from Temporal lobe and rest from Frontal, Parietal lobes and Central and Para central areas. All the patients suspected of Dissociative disorder had normal 
findings in EEG. Interestingly enough, most of the patients among the undiagnosed subgroup at the time of referral had positive EEG findings 54\% (Table-V). In 14 patients, abnormal EEG was in the form of spike \& wave, and in 4 patients sharp \& wave.

\section{Conclusion:}

EEG is not routinely advised in patients suspected of primary psychiatric disorder. Whereas it has important role in classification and management of seizure disorders. Patients with epilepsy often have got psychiatric symptoms and co morbidities specially in temporal lobe epilepsy eg. complex partial seizure. On the other hand in patients with PNES symptoms, EEG might be helpful in differentiating from true seizure. So judicious use of EEG might be helpful in management of patients with psychiatric and neurological symptoms.

\section{References:}

1. Hughes JR, John ER."Conventional and quantitative electroencephalography in psychiatry". Journal of Neuropsychiatry and Clinical Neuroscience 1999; 11:190208.

2. Towle VL, Bolaños J, Suarez D, Tan K, Grzeszczuk R, Levin DN, Cakmur R, Frank SA, Spire JP. "The spatial location of EEG electrodes: locating the best-fitting sphere relative to cortical anatomy”. Electroencephalogr Clin Neurophysiol 1993; 86 (1):1-6.

3. Howard RC, "The clinical EEG and personality in mentally abnormal offenders”. Psychological Medicine 1984; 14: 569- 580.
4. Hill JDN, "Psychiatric aspects of epilepsy” Medical Press 1953:229:473- 475

5. Pond DA. "Psychiatric aspects of epilepsy". Journal of the Indian Medical Profession 1957; 3: 1441-1451.

6. Benbadis SR, Tatum WO, "Over intepretation of EEGs and misdiagnosis of epilepsy”. JClinNeurophysiol. Feb 2003; 20 (1): 42-4.

7. Benbadis SR, Lin K. Errors in EEG interpretation and misdiagnosis of epilepsy. Which EEG patterns are overread?. Eur Neurol 2008; 59(5):267-71.

8. Bruck I, Antoniuk SA, Spessatto A . "Epilepsy in children with cerebral palsy”. Arq Neuropsiquiatr 2001; 59(1):35-39.

9. Goulden KJ, Shinnar S, Koller H, Katz M, . "Epilepsy in children with mental retardation: a cohort study”. Epilepsia; Sep-Oct 1991; 32(5):690-7.

10. Gaitatzis A, Carrol K, Majeed A et al. "The epidemiology of the comorbidity of epilepsy in general population”. Epilepsia 2004; 45(12):1613-1622.

11. O’Sullivan SS, Mullins GM, Cassidy EM, McNamara B “The role of the standard EEG in clinical psychiatry". Hum Psychopharmacol. 2006 Jun; 21(4):265-71

12. Shrestha R, Pradhan SN, Sharma SC, Shakya KN, Karki DB, Rana BBS, Joshi LN “ A study of first 350 cases referred for EEG in Kathmandu medical college teaching hospital”. Kathmandu University Medical Journal 2004; 2(1): 24-27

13. Van Sweden B, DE Bruecker G "Patterns of EEG dysfunction in general hospital psychiatry". Neuropsychobiology 1986; 16: $131-134$

14. Lam RW, Hurwitz, TA Wada, "Clinical use of EEG in a general psychiatric setting” Hospital and community psychiatr 1988; 9: $533-536$ 